\title{
DOE/PC/93203--T/O
}

\section{ELECTROSTATIC BENEFICIATION OF COAL}

Identification Number: DE-FG22-93PC93203

Grant Period: October 1, 1993 to September 31, 1996

\section{QUARTERLY TECHNICAL PROGRESS REPORT \\ January 1, 1996 to March 31, 1996}

Submitted by

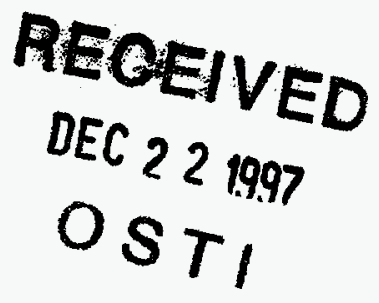

M. K. Mazumder (PI), D. Lindquist (Co-PI), and K. B. Tennal (Co-PI)

University of Arkansas at Little Rock

2801 S. University

Little Rock, AR 72204

Submitted to

Document Control Center

U.S. Department of Energy

Pittsburgh Energy Technology Center

PO BOX 10940, MS 921-118

Pittsburgh, PA 15236-0940

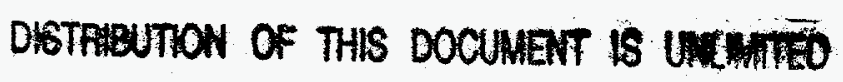

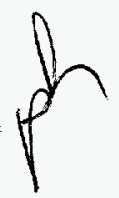

April 1996

U.S./DOE Patent Clearance is not required prior to publication of this docưment.

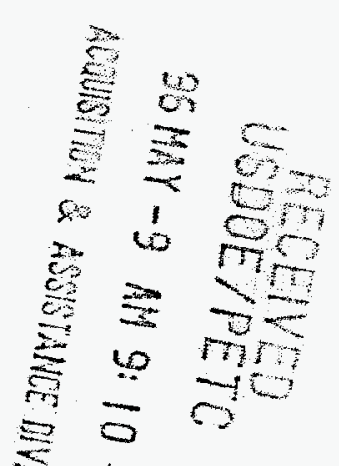




\section{DISCLAIMER}

This report was prepared as an account of work sponsored by an agency of the United States Government. Neither the United States Government nor any agency thereof, nor any of their employees, makes any warranty, express or implied, or assumes any legal liability or responsibility for the accuracy, completeness, or usefulness of any information, apparatus, product, or process disclosed, or represents that its use would not infringe privately owned rights. Reference herein to any specific commercial product, process, or service by trade name, trademark, manufacturer, or otherwise does not necessarily constitute or imply its endorsement, recommendation, or favoring by the United States Government or any agency thereof. The views and opinions of authors expressed herein do not necessarily state or reflect those of the United States Government or any agency thereof. 


\section{DISCLAIMER}

Portions of this document may be illegible electronic image products. Images are produced from the best available original document. 


\section{ELECTROSTATIC BENEFICIATION OF COAL DOE PROJECT ID\#: DE-FG22-93PC93203}

Quarterly Technical Progress Report

January 1, 1996 to March 31, 1996

\section{INTRODUCTION}

This report outlines the progress made during the tenth quarter of the project, from January 1, 1996 to March 31, 1996.

\section{WORK PERFORMED IN THE TENTH QUARTER}

\section{Charge Decay Measurement on the Separator Plates}

Two methods of examining the decay rate of charge on powders deposited on the separator plates were examined. In the first method the charge transferred from ground to the separator plate was measured directly with an electrometer after completion of the powder deposition and after turning off the electric field. In a second method (also described in the ninth quarter report) an electrostatic field meter (Trek model 354A) was used to measure the field due to the charge on the plates or on thin Teflon or aluminum plates which had been placed over the metal separator plates.

Electrometer method. In general it should not be possible to measure the charge decay directly by this technique. When the positive charge moves onto the conducting plate it simply combines with its image charge with no current passing through the electrometer. Indeed the charge measured in this way amounted to only $2 \%$ of the total charge deposited on the plates. That some charge is measured could be explained if the image charge does not exactly equal the charge on the particles. They may not be equal since the powder is not enclosed by the plates in a Faraday cage arrangement so that all electric field lines from the particles may not terminate on the plates. Also measured by this method would be charge leaving the plate by some other means than conduction between the powder and the plate, such as discharge into the air or charged particles falling off of the plate. There are, thus, questions as to the exact meaning of these measurements. However, this method of observing charge decay has the advantage that 
measurements can begin immediately after deposition of the powder. No time is lost in opening the separator and in removing the plates.

Several runs were made with the electrometer connected to each of the two separator plates. Coal powder was passed through the static tribocharger and into the separator. A $10 \mathrm{KV}$ potential difference was used across the separator plates. The separator voltage was turned off and the electrometer was read every few minutes. The first reading was usually one to two minutes after the beginning of the deposition. A Mathcad program was developed to fit the data and determine the time constant of the charge decay. The measured charge as a function of time is given by

$$
\mathrm{q}=\mathrm{q}_{0}-\mathrm{q}_{0} \exp (-\mathrm{t} / \tau),
$$

where $q$ is the charge at time $t, q_{0}$ is the measured charge for $t \gg \tau$, and $\tau$ is the time constant for charge decay.

Data and best fits of the data to equation (1) are shown in figures 1 and 2 for the negative and positive plates, respectively. The $P \times 1$ vectors give $q_{0}$ (in units of $10^{-7} \mathrm{C}$ ) and $\tau$ (in minutes), from top to bottom, respectively. The fits for an exponential decay are not particularly good suggesting that a single exponential decay mechanism may not give an adequate description of the decay. We thus considered that two decay mechanisms might be active each having a different time constant and a different final value. Discharge to the atmosphere, for instance, would require electric fields above a certain level so that when charge dropped below some value, discharge to the air would cease.

We consider one mode of decay with time constant $\tau_{1}$, to be active only as long as the charge remaining on the plate is above some level. This level corresponds to a measured charge, $\mathrm{q}_{1}$, on the electrometer. The second mode of decay with time constant $\tau_{2}$, will be active until the charge on the plate reaches zero (a conductive mode, for instance) or in this case until the dissipated charge reaches some final value, $\mathrm{q}_{0}$. The equation for the charge measured on the electrometer based on this dual exponential decay is

$$
q=q_{0}\left(1-e^{-\frac{t}{\tau_{2}}}\right)+q_{1}\left(1-e^{-\frac{t}{\tau_{1}}}\right) e^{-\frac{t}{\tau_{2}}} .
$$


The fits of the data for this equation are also shown in figures 1 and 2. The $P \times 2$ vectors give $q_{0}$ and $\mathrm{q}_{1}\left(10^{-7} \mathrm{C}\right)$ and $\tau_{1}$ and $\tau_{2}$ (minutes), from top to bottom, respectively.

Charge to mass ratios were around $3 \mu \mathrm{C} / \mathrm{g}$ and $9 \mu \mathrm{C} / \mathrm{g}$ for the negative (clean) plate and positive (refuse) plate, respectively. For the negative plate the average time constant for charge decay using the single exponential fit for four runs was 3.15 minutes with a standard deviation of 0.8 minutes. The time constant for the positive plate was about 2.4 minutes. The two component decay method provided better fits to the data. To give meaning to the two decay time constants we will need to identify the decay mechanisms that are being measured.

Field meter method. Thin $(0.8 \mathrm{~mm})$ aluminum plates were taped to the separator plates. After deposition of the charged coal powder the thin plates were removed from the separator and placed on a grounded metal surface. An electrostatic voltmeter was placed $4 \mathrm{~mm}$ above the plates. A data logging system was connected to the meter for automatic data collection.

Data for these measurements are presented in Figures 3, 4, and 5 for the clean plate, refuse plate, and filter, respectively. A single exponential decay again did not give a particularly good fit to the data. The equation for two decay mechanisms is

$$
V=\left(V_{0}-V_{1}\right) * \exp \left[-\left(\frac{t}{\tau_{1}}+\frac{t}{\tau_{2}}\right)\right]+V_{1} * \exp \left(-\frac{t}{\tau_{2}}\right)
$$

where $V_{0}$ is the potential at $t=0, V_{1}$ is the potential below which the first decay mechanism is inactive, and $\tau_{1}$ and $\tau_{2}$ are the time constants for charge decay for the two decay mechanisms. The elements of matrices $P \times 2$ give, from top to bottom, the best fit values for $V_{0}$ and $V_{1}$ in volts and $\tau_{1}$ and $\tau_{2}$ in seconds, respectively. A formula is available relating the charge density on the plates to the potential reading. It needs to be verified for our situation.

We have means of measuring the decay of charge on deposited powders. We now need to consider the measurements in light of the many variables, particularly the mass of powder and/or thickness of the powder layer, the magnitude of the starting charge, the size of the particles, and the temperature and relative humidity. We expect that the refuse plate should contain more conducting particles which should give a faster charge decay. This appeared to be the case with the electrometer readings but not with the field meter readings. 


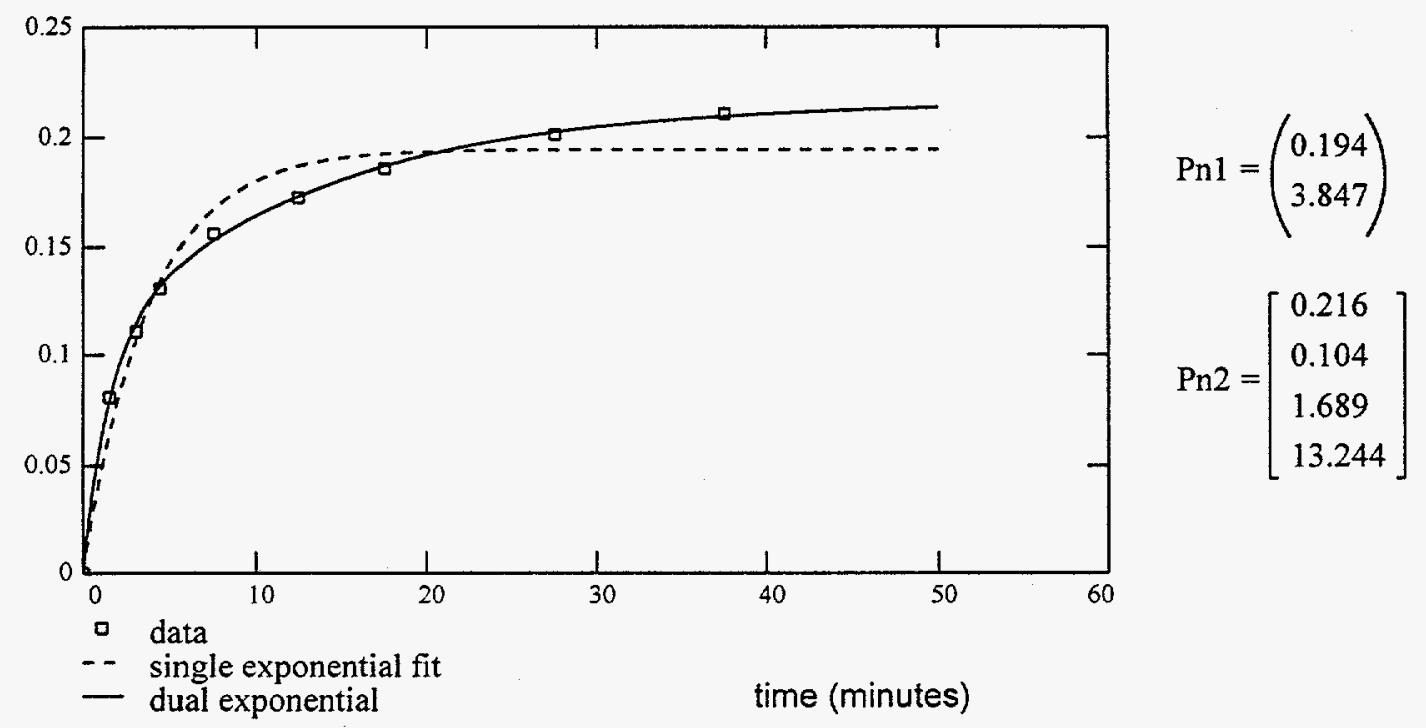

Figure 1. Exponential fits to the charge decay of Illinois No. 6 coal powder deposited on the negative plate of the separator. See text for an explaination of the dual exponential fit.

$\mathrm{i}:=0 . .6 \quad \mathrm{t}:=0, .2 . .15$

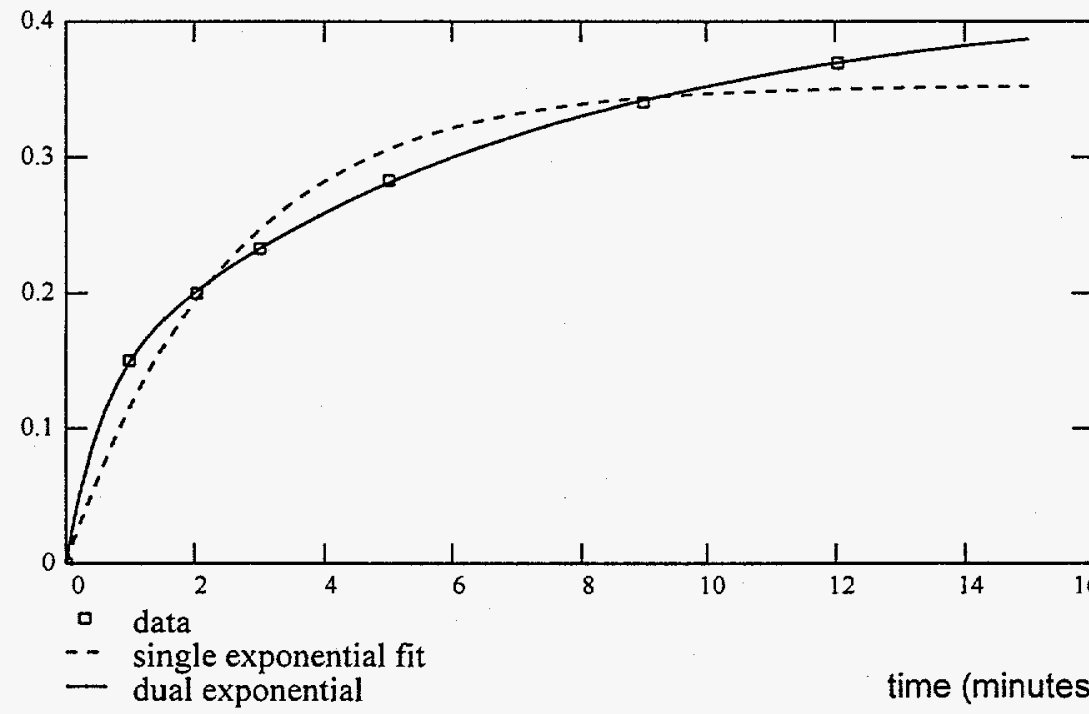

$\operatorname{Pp} 1=\left(\begin{array}{l}0.353 \\ 2.493\end{array}\right)$

$\operatorname{Pp} 2=\left[\begin{array}{l}0.417 \\ 0.13 \\ 0.577 \\ 6.712\end{array}\right]$

Figure 2. Exponential fits to the charge decay of Illinois No. 6 coal powder deposited on the positive plate of the separator. See text for an explaination of the dual exponential fit. 


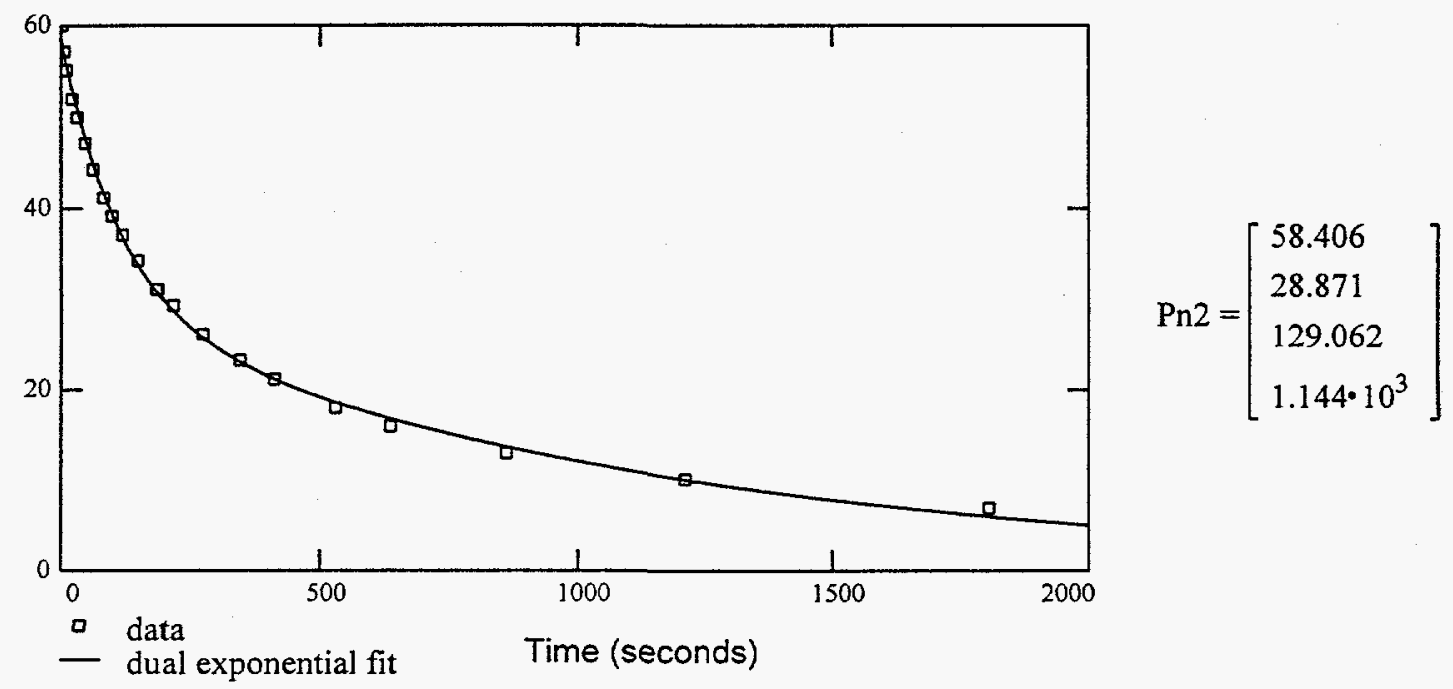

Figure 3. Charge decay of Illinois No. 6 coal powder deposited on the negative plate of the separator as measured with an electrostatic potential meter. $\mathrm{Pn} 2$ gives the parameters for fitting to a dual exponential decay. The first element is the starting potential. The second is the potential at which the first decay mechanism becomes inactive. The third and forth elements are the time constants for the two decay mechanisms. See text for an explanation of the dual exponential fit.

$\mathrm{i}:=0 . .23 \quad \mathrm{t}:=0,10 . .2000$

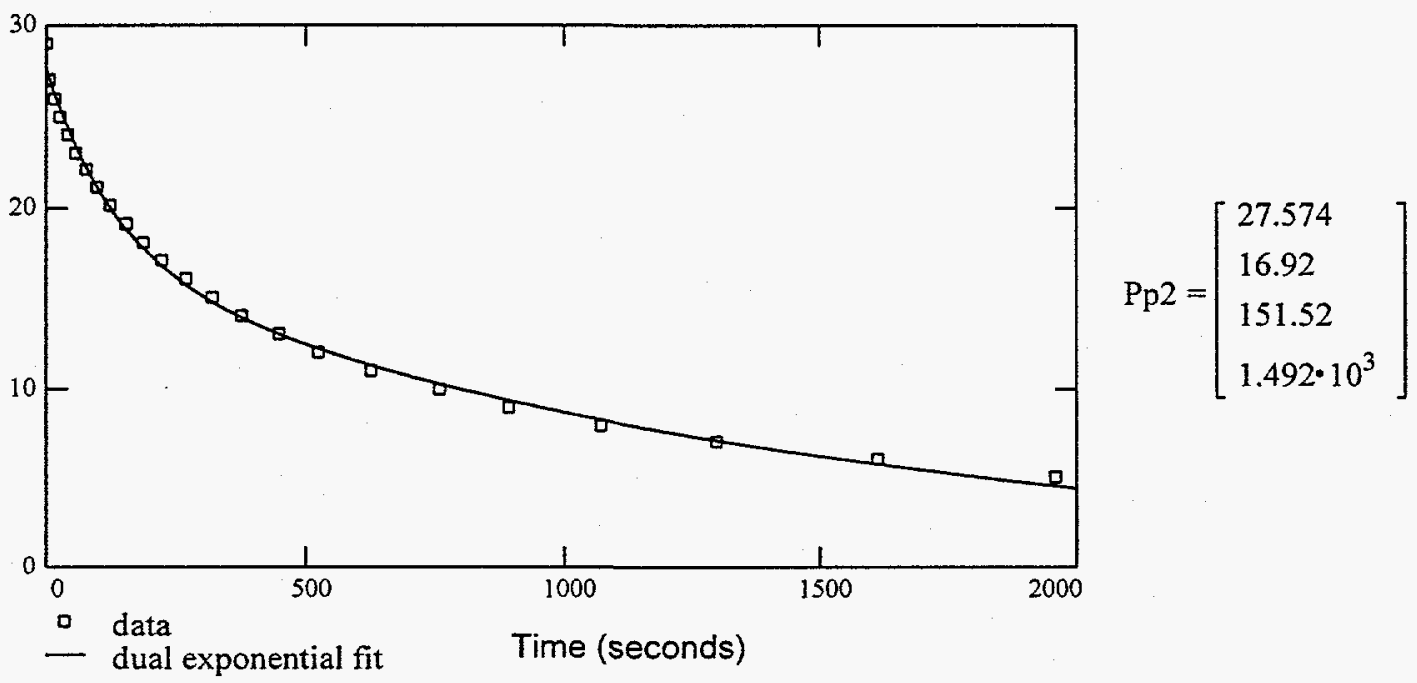

Figure 4. Exponential fit to the charge decay of Illinois No. 6 coal powder deposited on the positive plate of the separator. See Figure 3 caption and the text for an explanation of the dual exponential fit. 
$\mathrm{i}:=0 . .29 \quad \mathrm{t}:=0,20 . .6000$

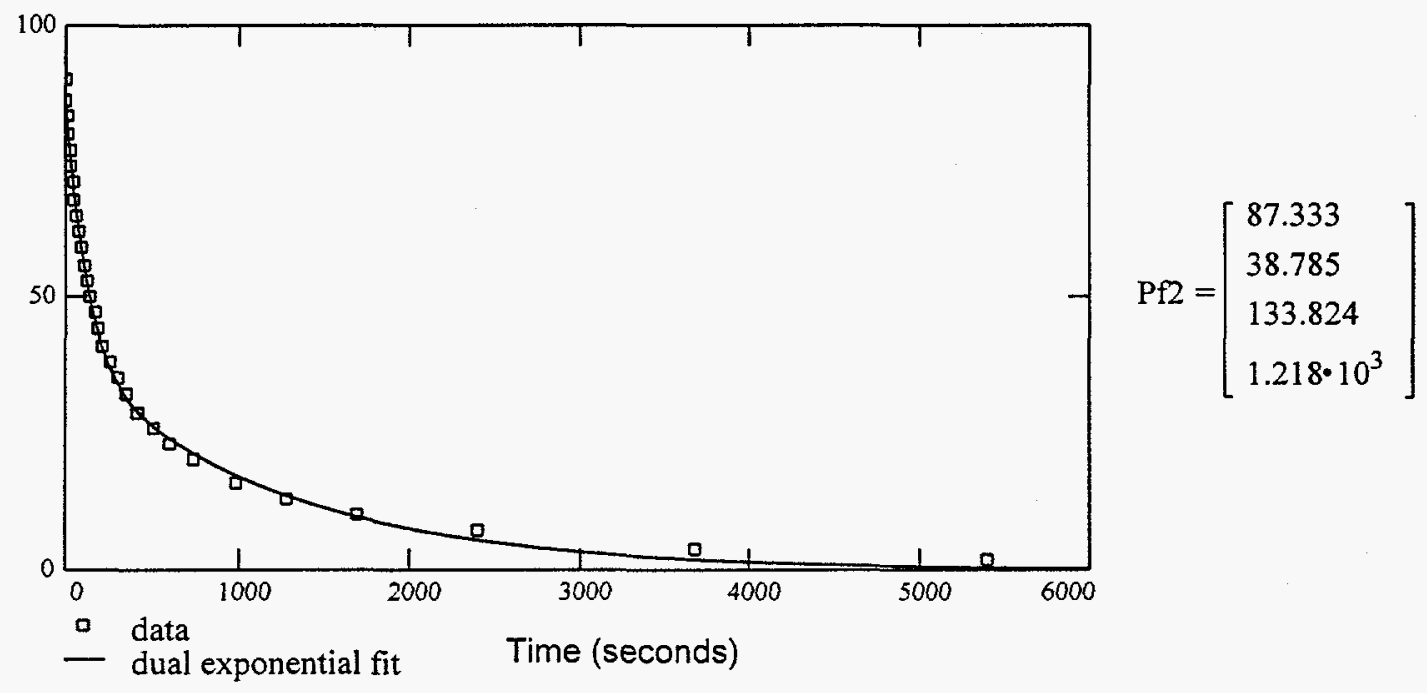

Figure 5. Exponential fits to the charge decay of Illinois No. 6 coal powder deposited on the filter at the bottom of the separator. See Figure 3 caption and the text for an explaination of the dual exponential fit. 


\section{Resistivity of coal powder}

A resistivity cell was constructed from a PVC cylinder. The cell was $110.23 \mathrm{~mm}$ inner diameter and $10.025 \mathrm{~mm}$ thick. This cylinder was placed on a flat aluminum plate. It was filled with ground coal powder and another aluminum plate was placed on top and held with a piece of lead. A potential difference, $\mathrm{V}$, of $14.95 \mathrm{~V}$ was applied across the two aluminum plates and the current, I, through the circuit was measured with an electrometer. Resistivity, $\rho$, was calculated by

$$
\rho=\frac{V}{I} \frac{A}{l},
$$

where $\mathrm{A}$ is the cross sectional area of the cell and $l$ is its thickness. There appears to be a relationship between the resistivity and particle size. The values fall within the range determined by others

Table 1. RESISTIVITY DETERMINATIONS FOR ILLINOIS No. 6 COAL POWDER

\begin{tabular}{|l|c|c|c|}
\hline & Mass of Coal $(\mathrm{g})$ & Current $(\mathrm{A})$ & Resistivity $(\Omega \mathrm{m})$ \\
\hline fine ground $^{1}$ & 61.83 & $1.5 \times 10^{-10}$ & $0.948 \times 10^{11}$ \\
\hline coarse ground $^{2}$ & 77.14 & $0.54 \times 10^{-10}$ & $2.63 \times 10^{11}$ \\
\hline fine ground (repeat) $^{1}$ & 69.24 & $1.25 \times 10^{-10}$ & $1.14 \times 10^{11}$ \\
\hline
\end{tabular}

\footnotetext{
${ }^{1}$ Ground with the microhammermill with $0.8 \mathrm{~mm}$ screen. MMD about $200 \mu \mathrm{m}$.

${ }^{2}$ Ground with hand grinder. MMD about $2 \mathrm{~mm}$.
} 


\section{Charging of Small Particles by Milling}

We continued our investigation into the charging of small particles by milling with copper beads and copper coated iron beads. An introduction to this technique is described in the ninth quarter report.

With our homemade blowoff cup it was not always possible to remove all of the coal powder from the carrier beads. A new blowoff cup was obtained, which had been designed and constructed by a toner manufacturer. In the new cup significant agitation of the particles occurred such that the copper coating on the copper coated iron was worn away and some types of copper particles were actually ground so that a continuous flow of copper dust left the cup. It was necessary to reduce the air pressure into the cup to find a flow rate at which coal particles could be removed with minimal removal of the copper coatings.

\section{Observations with Silica-gel}

The charging of single component particles in the static tribocharger is of interest. It is suspected that bipolar charge distribution will nearly always be seen as a result of particleparticle collisions. Silica gel was used for these tests.

Silica gel particles in the size range or about 90 to $300 \mu \mathrm{m}$ were passed through the static tribocharged and the separator. Most of the particles went to the positive plate of the separator. However some were observed to rebound from the plate and then cross to the negative plate. When the positive plate was tapped from the backside some of the particles came off and crossed to the negative plate. When the negative plate was tapped larger particles dropped to the filter but at an angle toward the positive plate. Apparently there is a charge exchange due to contact or conductive induction or both, between the silica gel particles and the aluminum plate. Of interest is whether or not this phenomena also occurs with the coal particles resulting in a reduction in the beneficiation or in the clean fraction recovered.

Effect of feed rate. Two different feed rates were used averaging $0.1 \mathrm{~g} / \mathrm{min}$. and 1.2 $\mathrm{g} / \mathrm{min}$. The net charge transferred to the silica gel was the same for the two rates at $4.7 \mu \mathrm{C} / \mathrm{g}$. The fraction of mass collected from the positive plate was $44 \%$ and $26 \%$ for the low and high feed rates, respectively, and $4.8 \%$ and $4.1 \%$ from the negative plate, respectively. It is suspected 
that the higher concentration of particles lead to a large mutual repulsion force causing loss of particles within the expansion cone.

\section{Contact charging review}

We are also reviewing recent articles on particle charging. Of particular interest are papers discussing the importance and mechanisms of electrical breakdown of the surrounding gas in contact charging. ${ }^{1,2}$ Though neither of these papers deals with single particles in the size range of the coal powders used in electrostatic beneficiation, they both indicate that multiple contacts will be needed to obtain optimum charging and that if a particle enters the impact with a charge of opposite polarity to that desired a single contact may not be sufficient to reverse the polarity.

Velocity of impact was found to affect the rate at which a particle approaches its equilibrium charge but not the magnitude of that equilibrium charge. We observe higher net charge for higher gas velocity through the static tribocharger. Thus, particles may not be receiving sufficient numbers of impacts to reach their equilibrium charge levels. The change may result from smaller particles impacting more efficiently at the higher velocities.

1 Tatsushi Matsuyama and Hideo Yamamoto, "Charge relaxation process dominates contact charging of a particle in atmospheric conditions," J. Phys. D: Appl. Phys. 28 (1995) 2418-2423.

${ }^{2}$ Bernhard A. Kwetkus, Klaus Sattler and Has-Christoph Siegmann, "Gas breakdown in contact electrification," J. Phys. D: Appl. Phys. 25, 139-146 (1992).

H.A. Elghazaly and G.S.P. Castle, "The charge limit of liquid droplets due to electron avalanches and surface disruption," pp. 121-6, in Electrostatics 1987, Inst. Phys. Conf. Ser. No. 85, IOP Publishing, Ltd., Bristol, England and Philadelphia, PA, 1987.

N. Hamamoto, Y. Nakajima, and T. Sato, "Experimental discussion on maximum surface charge density of fine particles sustainable in normal atmosphere," Journal of Electrostatics, 28 (1992) 161-173.

\section{Tribocharging model}

A model is being developed and a manuscript is in preparation regarding triboelectric charging of different types of macerals. A first draft of the manuscript follows. 


\title{
Electrostatic Charging Properties of Coal Macerals
}

\author{
David Lindquist \\ Draft 5/6/96
}

\section{Introduction:}

Many are familiar with the ancient demonstration of static electricity, that of rubbing amber with fur, giving the amber an attraction for objects such as paper scraps. It is not surprising that coal can also be charged since, like amber, it is derived from ancient organic matter. In fact the coal maceral liptinite is chemically identical to amber, the difference being merely of size; liptinite is typically of micron dimensions. Other maceral types in coal such as vitrinite and inertinite, may also be electrostatically charged.

These charging properties exploited in electrostatic beneficiation which is a potential alternative to currently used methods of removing pyrite and other minerals from coal prior to combustion. In the electrostatic cleaning method, coal is first pulverized to a fine powder of particles $5-750 \mu \mathrm{m}$ in diameter. The powder then is electrostatically charged by impaction against a metal surface such as copper. On contact with copper, the organic coal particles become positively charged and pyrites along with other inorganic mineral particles become negatively charged. This powder, after tribocharging, passes through an electrostatic separator consisting of two conducting plates across which a high voltage is applied. The powder then separates on the basis of the polarity of charge on the individual particles.

Currently, pyrites are removed from coal on a large scale by flotation from water slurries with the aid of thiocarboxylate surfactants. Despite the success of flotation, there 
are distinct disadvantages. The clean coal must be dried before combustion and large volumes of aqueous waste must be dealt with. Electrostatic beneficiation is a very attractive alternative since the drawbacks of wet cleaning are absent. However, several fundamental factors that influence the tribocharging and separation process are not fully understood; there is considerable uncertainty in the successful operation of this process, hence preventing its commercial implementation to date.

The goal in our studies is to develop a comprehensive model for charging which encompasses the properties of the major components of coal, both maceral and mineral, so that electrostatic beneficiation may become commercially viable. The focus of this paper is on the different electrostatic charging behavior among the various maceral types. Based on the observed differences, a correlation between charge properties and chemical composition of each maceral type is proposed.

\section{Chemical Structure of Macerals and its Relationship to Charging:}

Before presenting the experimental work, a brief description of the proposed relationship between the chemical structure of macerals and their charging properties is in order. The dark maceral inertinite has a large proportion of aromatic carbon and therefore is the maceral which most resembles graphite. Inertinite may be presumed generally to be the best electrical conductor among macerals due to electron delocalized pi bonding.

Vitrinite, the predominant maceral of coals, is derived from the most abundant components of plants, namely cellulose and lignin. Vitrinite has some aromatic character [1] due in part to its phenolic lignin precursor. However, vitrinite also has a significant oxygen content. Both the carbohydrate cellulose and phenolic lignin contain oxygen. Vitrinite is therefore a step removed from inertinite in comparison with graphite; the oxygen content of vitrinite diminishes electron delocalization and electrical conductivity is expected to be decreased. 
The third major maceral type, liptinite, has perhaps the most interesting electronic structure as manifest by its intense fluorescence stimulated by blue or ultraviolet light. Liptinite, derived from fatty structures such as found in seeds and spores, is rich in hydrogen from aliphatic carbon and is also low in oxygen. The fluorescence property is due to electron delocalized structures also present in this maceral. Examples of coal structures which may give rise to fluorescence include terpenes and small aromatic structures. The low abundance of oxygen in this maceral is favorable for fluorescence since heteroatoms most often quench fluorescence.

The question arises as to whether the good charging properties of amber (and its smaller sized relative liptinite) are related to their fluorescent properties. Fluorescence phenomena in organic molecules is a complex process usually resulting from $\pi^{*} \rightarrow \pi$ electronic transitions in aromatic or conjugated olefin species. A simplified illustration of some molecular orbital electronic states are illustrated in Figure 1.

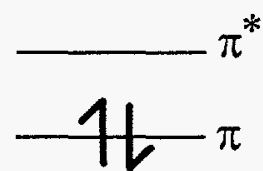

Ground State Singlet

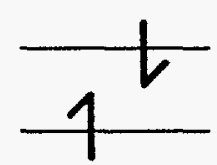

Excited State Singlet

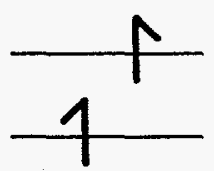

Triplet State

\section{Figure 1. Three orbital states for an electron pair}

In the most rudimentary description of fluorescence, a metastable excited state singlet [Figure 1 (middle)] is first produced by light stimulation. The $\pi^{*}$ electron then returns to the ground state and light is emitted with the decrease in energy of the system. The lifetime of the excited singlet is on the order of $10^{-8}$ seconds.

Most coal electrostatic studies, including our own, indicate that coal macerals prefer to lose electrons and adopt a positive rather than negative electrostatic charge. 
Perhaps the metastable excited electronics states which produce fluorescence in liptinite, are the same electronic states which provide a means for transfer of electrons out of the maceral during tribocharging [2]. In this scenario, a small proportion of the outer $\pi^{*}$ orbitals of the maceral would be populated with electrons and these electrons could be removed when the maceral is contacted with an electron acceptor such as the grounded copper plate used for electrostatic beneficiation. Only a very small number of electrons must be transferred during tribocharging in order to develop a significant charge useful for the beneficiation process. Conversely, it may also be possible to affect a significant negative charge in liptinite since one could also feed electrons into the metastable excited states as opposed to removing electrons. For example this could be accomplished by a corona discharge since electrons have the highest mobility among anions. However, this negative charging would not be expected in contact electrification with grounded copper as is generally performed in electrostatic beneficiation. Copper is an electronegative metal.

A process related to the fluorescence observed in liptinite and amber is that of phosphorescence. Phosphorescence results from decay of the triplet state shown in Figure 1. The triplet state producing phosphorescence is longer lived than the excited state singlet of fluorescence since return to the ground state is spin forbidden in the triplet case. The lifetime of the triplet ranges from approximately $10^{-3}$ seconds to 10 seconds. Formation of the triplet is a multistep process. The electron in the ground state is first promoted to an excited singlet energy followed by a change in the electron spin. It should be noted that phosphorescence is not a general feature of coals and is much less common in nature than is fluorescence.

If this model has any validity, then it should be possible to enhance charge beneficiation by promoting fluorescence. For example, fluorescent agents could be added to coal powder prior to charging in order to enhance the charging of other macerals such as vitrinite and inertinite. A quick means of screening potential agents would be to repeat 
the toner experiment described above using a polished coal surface treated with a fluorescent compound to note any changes in where the toner sticks to the surface. Another approach would be to use blue or ultraviolet light illumination at the copper plate during tribocharging to promote formation of excited electronic states, thus encouraging electron transfer. Phosphorescence might be a better aid to charge transfer than fluorescence since the triplet excited state is longer lived than the excited singlet. However, since phosphorescence is not a natural property of coal macerals it would have to be induced by additives.

Why does the intensity and wavelength of fluorescence vary greatly among the different macerals in coal? These questions of course have already been thoroughly addressed by others and this knowledge may be helpful in understanding electrostatic beneficiation. As stated above, the general requirements for fluorescence in organic compounds are accessible and metastable $\pi^{*}$ excited states. The stability of the excited $\pi^{*}$ state is dependent upon this molecular orbital being delocalized over several atoms. If however delocalization involves too many atoms, then the band gap between the $\pi$ and $\pi^{*}$ is narrow and the stability of the excited state collapses. This is what occurs for example in the macerals vitrinite and inertinite, which both have extensive aromatic structure and therefore little or no fluorescence. In the case of liptinite, the requisite aromatic and olefinic character is present, but the larger percentage of hydrogen and hence aliphatic carbon present in liptinite restricts the delocalization to say between 10 and 20 carbon atoms. Liptinite fluorescence is quite intense in bituminous and subbituminous coals. As coal rank increases however, liptinite fluorescence shifts to longer wavelengths and diminishes in intensity. This observation is consistent with the increasing aromatization of the liptinite with increasing rank. In anthracite the pseudographitic structure is highly developed in all macerals so that they become indistinguishable with the increased aromaticity $[3,4]$. 
Other atoms besides carbon influence the energies of conjugated $\pi$ systems and hence their fluorescence behavior. For example oxygen and nitrogen are structural components of many fluorescent molecules. Quinoline, a nitrogen containing heterocycle, exhibits intense fluorescence. Coals of the Eastern United States, prime candidates for electrostatic beneficiation because of their high pyrite content, contain large quantities of nitrogen for the same reason that they have pyrite, namely bacteria. Eastern U.S. coals originated in river delta salt marsh environments conducive to bacterial growth. Sulfur bacteria in the ancient marshes were the source of the fine pyrites found in these coals and the relatively high nitrogen content of these coals arose from the bacterial proteins [5].

\section{Experimental:}

In contrast to coal beneficiation, the xerographic photocopy process is a well controlled electrostatic technology. Toner powders that consistently adopt a specific charge polarity are used in copiers today. The stable electrostatic properties of a commercial toner powder (Minolta ${ }^{\circledR}$ MT Color Toner II) were used to probe the charging properties of macerals in Illinois No. 6 coal. In these experiments, charged toner powders were deposited onto coal specimens and subsequently observed under a microscope to see which macerals the toner was attracted to.

The coal samples were prepared by grinding a planar surface perpendicular to the bedding plane of approximately one inch square pieces of coal. The final polish of the surface was achieved by rubbing the sample on the back of an index card using wetted 0.3 $\mu \mathrm{m}$ alumina powder as a polishing aid. The alumina was then rinsed off of the coal under running water. The samples were towel dried and the polished surface heated briefly for a few seconds with a heat gun to remove remaining volatile water from the coal. 
Two different methods then were used to deposit negative polarity toner onto the coals. For the first method, a high frequency spark generator (Tesla coil) was positioned several inches above the coal on the lab bench and toner powder was sprinkled through a fine copper mesh above the coil onto the coal. The net effect of the method was to create a rain of negatively charged powder depositing onto the coal. After deposition, excess toner was removed from the coal by turning the sample on its side and striking against the table surface.

For the second method, charged toner powder was deposited in a similar fashion, except that prior to deposition the coal was tribostatically charged against copper metal. To tribocharge the sample, it was first placed face down for several seconds into an electrically grounded vibrating bed of fine copper beads. Agitation was accomplished by clamping the bed to a vibratory feeder. The sample was then removed from the bed and the negative toner powder deposited in a similar manner as above. The difference between the two methods therefore, is that in the first method the coal was not charged prior to toner deposition.

The powder coated samples were then observed under fluorescing conditions in a microscope (Nikon Labophot $\left.{ }^{\circledR}\right)$ using vertical illumination. The fluorescence illumination was induced by blue light filtered from a mercury lamp source.

\section{Results and Discussion:}

Some toner adhered to each of the three maceral types using both deposition procedures. However, the first method yielded deposition preferentially onto the inertinite macerals, whereas the toner adhered preferentially to liptinite macerals by the second method. Figure 2 is a photomicrograph of Illinois \#6 coal showing preferential deposition of toner powder on inertinite. 


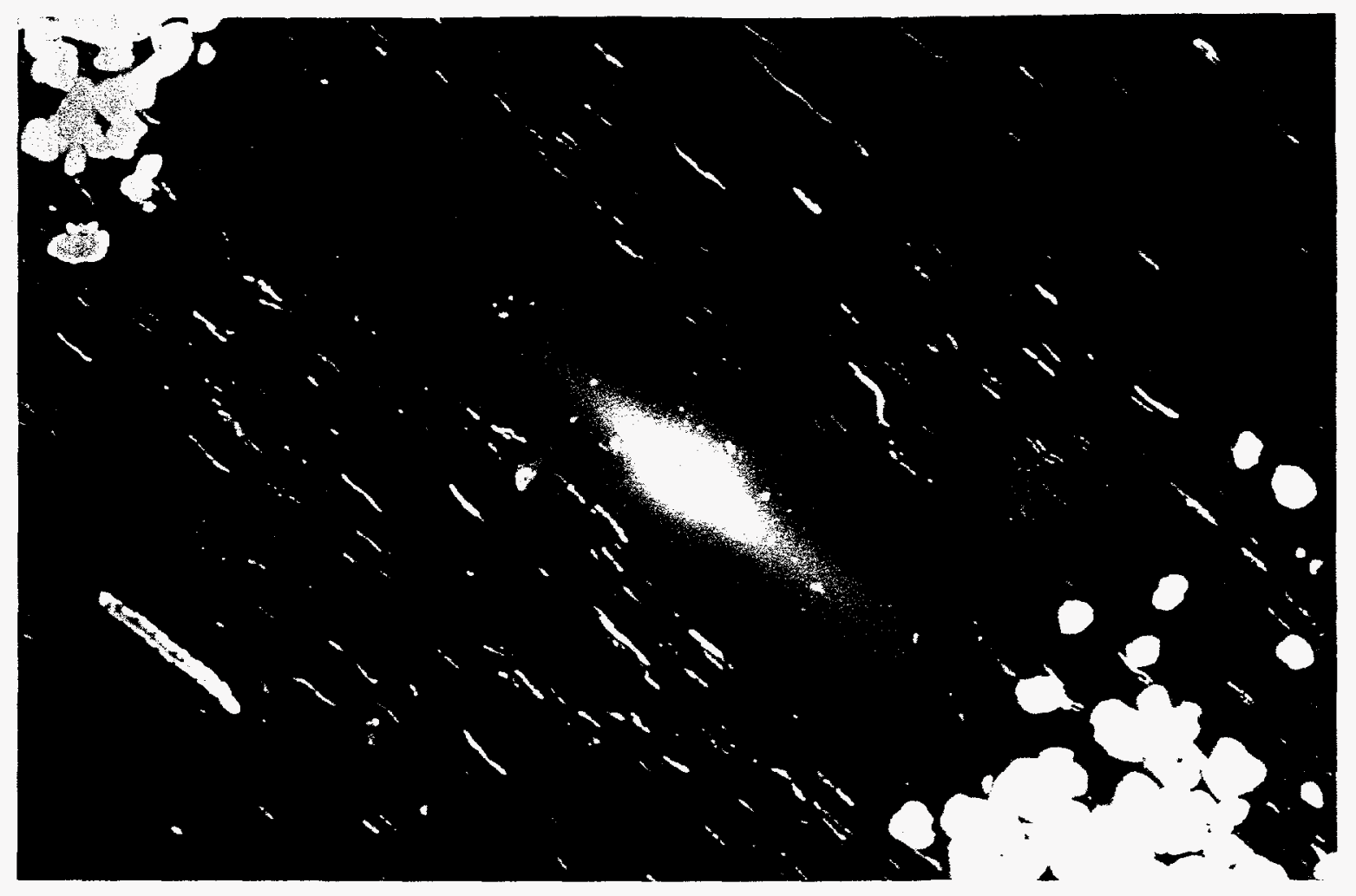

Figure 2: Negatively charged toner adhesion on inertinite.

The powder was plowed away with a toothpick so that the inertinite underneath may be clearly seen. Note the undisturbed toner on the edges of the inertinite in Figure 2.

Since the coal is not charged prior to deposition in the first method described, adhesion of the toner powder to the coal is dependent upon induction charging. That is, as the negatively charged toner approaches the coal, an opposite positive charge is induced in the coal surface. The induced mirror charge provides the attractive binding force for the powder. Electrically conducting materials are most amenable to inductive charging since charge may be drained from them easily when influenced by an approaching repulsive charge. This is in agreement with the fact that the powder adhered predominantly to inertinite.

Figure 3 is a photomicrograph of deposition seen using the second method of copper contact charging of the coal prior to depositing the toner. 


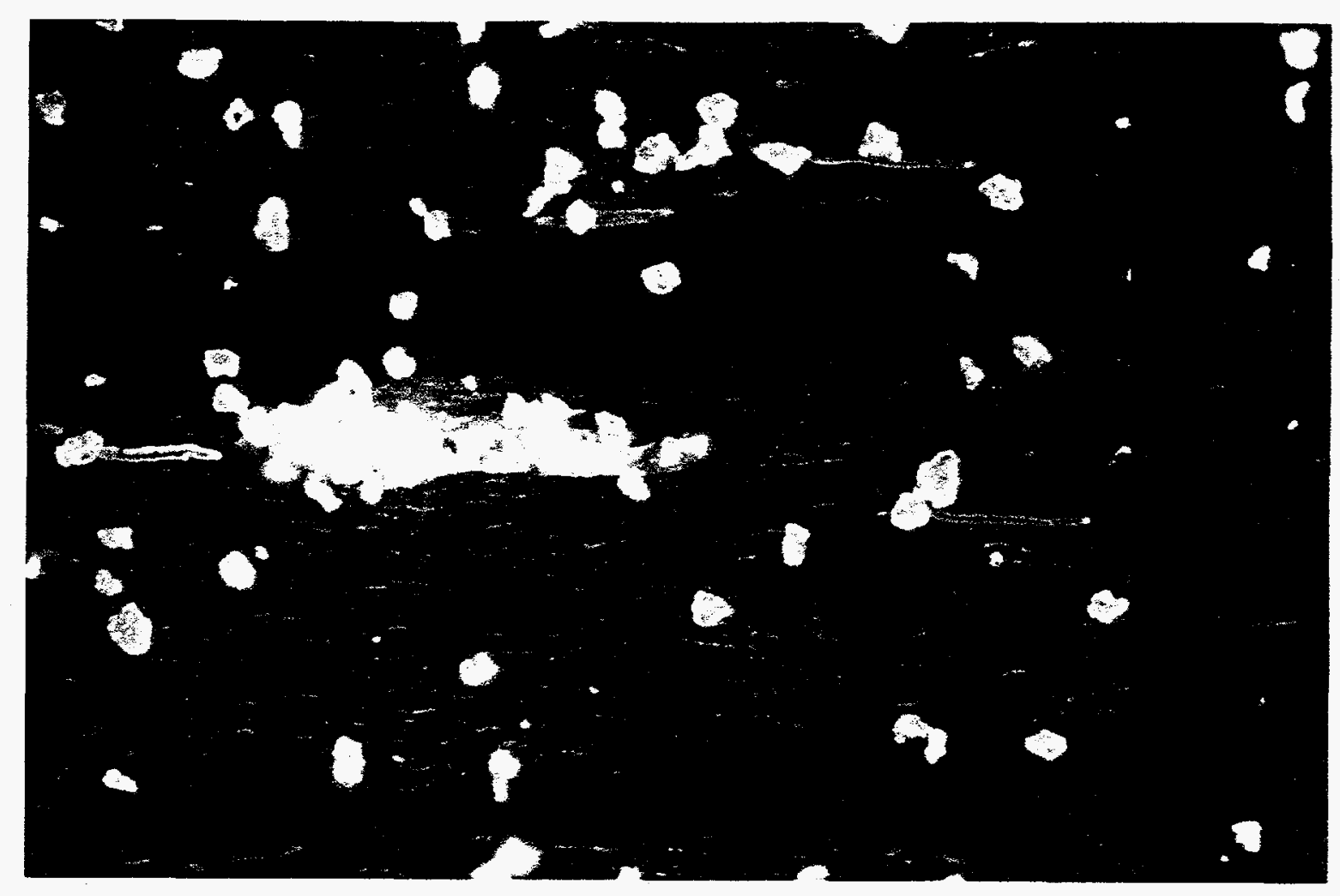

Figure 3: Negative toner deposited onto a tribocharged Illinois \#6 coal surface showing preferential deposition on liptinite.

We believe the different results obtained by the second method reflect the greater charge capacity of liptinite which may be related to its fluorescent properties. Preferential adhesion of toner to inertinite is not seen in the second method since during tribocharging the conductive inertinite readily transfers charge to liptinite.

These two experiments illustrate the extremes of macerals and their charging properties. Under the mild conditions of induction charging inertinite most easily adopts charge due to its conductivity. Conversely, the is an activation barrier to charging liptinite, a poor conductors as manifest by its fluorescent properties. However, the liptinite may hold a greater magnitude and more stable charge among macerals once the barrier to charging is exceeded by prolonged contact with copper. Vitrinite, being more 
or less intermediate in composition between liptinite and inertinite is less subject to preferential charging by either induction or contact charging.

One may speculate on the known deleterious effect of oxidation on maceral and mineral separation by electrostatic beneficiation as relates to these studies. For example it has been shown that fluorescence in coals diminishes with progressive oxidation [6,7].

Oxygenation results in a diminution of aromatic structure in coals $[8,9,10]$. The aromatic structure is important for both induction and contact charging of the macerals. It is imperative that electrostatic beneficiation be conducted on freshly ground coals since oxidation is largely irreversible, particularly on low rank bituminous and subbituminous coals [11]. It would certainly be desirable if one could easily perform reduction of oxidized coal surfaces to aid beneficiation. However, there is a plethora of readily performed oxidation reactions with coals $[12,13]$ but not reductions.

\section{REFERENCES}

1. Lin, R.; Ritz, G.P. "Studying individual macerals using i.r. microspectroscopy, and implications on oil versus gas/condensate proneness and "low-rank" generation" Org. Geochem. Vol. 20. No. 6, pp. 695-706, 1993. (vitrinite has more aromatic character than liptinite)

2. Lee, L.H. "Dual Mechanism for Metal-Polymer Contact Electrification" Journal of Electrostatics, 32 (1994) 1-29. (HOMO-LUMU discussion of charge transfer)

3. Mastalerz, M.; Bustin, R.M. "Variation in maceral chemistry within and between coals of varying rank: an electron microprobe and micro-Fourier transform infra-red investigation" Journal of Microscopy, Vol. 171, Pt 2, August 1993, pp. 153-166. (liptinite has more aliphatic and less aromatic than other macerals, vitrinite and semifusinite has more aliphatic than other inertinite macerals, similarities merge in anthracite)

4. Mastalerz, M.; Bustin, R.M. "Electron microprobe and micro-FTIR analyses applied to maceral chemistry" International Journal of Coal Geology, 24 (1993) 333-345. (as coal rank increases there is a decrease in carbonyl and aliphatic carbon and an increase in aromaticity in line with loss of hydrogen and oxygen with increasing rank) 
5. Wilfrid Francis, "Coal: Its Formation and Composition" Copyright 1954, Edward Arnold Publishers Ltd., London, pp. 494-496. (These pages discuss the inorganic content of fusains because of open cell structure, fusain formation is linked to biochemical process of coal formation; heat and microbial action partially destroyed "burned" the cell structure.

6. Bend, S.L.; Kosloski, D.M. "A petrographic examination of coal oxidation" International Journal of Coal Geology, 24 (1993) 233-243. (as coal becomes oxidized fluorescence diminishes)

7. Death, D.L.; Eberhardt, J.E.; Read, R. "Laser-induced macrofluorescence of coal: oxidation and macroalteration" Fuel, 1991, Vol. 70, September, pp. 1073-1077. (flourescence decreases with increasing oxidation)

8. Landais, P.; Rochdi, A. "In situ examination of coal macerals oxidation by microFT-i.r. spectroscopy" Fuel (1993), Vol. 72, No. 10, 1393-1401. (see increase in oxygenated moieties after oxidation)

9. Nkaji, F.E.; Thomas, K.M. "The effects of oxidation on the macromolecular structure of coal" Fuel 1995, Vol. 74, No. 6, pp. 932-937. (oxidation seen in IR, also there is a decrease in crosslinking density with oxidation: oxidized coals swell more with uptake of pyridine)

10. Yilmaz, M.; Ceylan, R.; Kara, H. "Changes in Coal Composition during Air Oxidation at Moderate Temperature" Energy Sources, 1989, Vol. 11, pp. 273-277. (oxidation of phenolic residues results in an increase in quinonoid structures)

11. Taraba, B. "Reversible and Irreversible Interaction of Oxygen With Coal of Various Rank" in Proceedings of the International Conference on Coal Science 16-20 September 1991, Butterworth-Heinemann Ltd., Oxford pp. 227-230. (oxygen adsorption is irreversible in subbituminous coals and reversible in anthracites)

12. Speight, J.G. "Oxidation and Coal Structure" in Coal Science and Technology 10; Coal Science and Chemistry, edited by A. Volborth, Elsevier, Amsterdam, 1987, pp. 183206. (example of oxidation reactions one can do on coal surfaces, remember there are NO articles on easy reductions one can do with coal)

13. González de Andrés, A.I.; Moinelo, S.R.; Tascón, J.M.D.; Bermejo, J. "Nature and mechanism of oxidation reactions occurring during coal chlorination" Fuel, 1992, Vol. 71, April, pp. 389-393. (another example of ease of oxidation reactions on coal) 